\title{
Insulin and heart failure
}

\author{
S. H. Taylor ${ }^{1}$
}

Insulin and glucose have long been known to be effective in experimental heart failure but there is still surprisingly little knowledge of their effects on cardiac function in man. Reawakening of interest in this relation has been occasioned by two recent findings. Firstly, the critical role of glucose in the metabolism of the failing anoxic heart has been precisely defined (Scheuer, 1967; Weissler et al., 1968; Owen, Thomas, and Opie, I969). Secondly, the finding that insulin release was suppressed in patients in heart failure (Taylor et al., 1969; Allison, Chamberlain, and Hinton, 1969; Sharma et al., 1970; Majid et al., 1971). A review of the current status of knowledge of this potentially important aspect of cardiac metabolism was, therefore, considered to be of interest to cardiological physicians and physiologists alike.

\section{Role of glucose and insulin in the meta- bolism of the failing heart}

Cardiac muscle uses a variety of substrates for the production of energy, the most important of which are free fatty acids, lactate, pyruvate, and glucose. Under normal physiological conditions fatty acids provide by far the major source of energy, lactate, pyruvate, and glucose supplying only a small part of the normal energy requirement of the heart. Though the heart is able to store small amounts of both lipid and glycogen, the major part of the energy requirements of the heart is run on a current account.

The transport mechanisms by which these various substrates enter the myocardial cell appear to be qualitatively similar to those present in other tissues. Lipids are first hydrolysed in the interstitial space before transport

into the cell; the entry of glucose into the myocardial cell is insulin dependent.

After entry into the myocardial cell, fatty

${ }^{1}$ Address: Cardiovascular Unit, University Department of Medicine, The General Infirmary, Leeds. acids, lactate, pyruvate, and glucose are metabolized to produce the high-energy adenosine-triphosphate. The myocardial cell differs conspicuously from other muscle cells in that the final step in this process in the heart is critically oxygen dependent. The emphasis on oxidative metabolism in the myocardial cell is reflected in the fact that any reduction in its oxygen tension immediately results in conspicuous changes in electrical activity and contractile performance of the heart (Tennant and Wiggers, 1935; Sayen et al., 1954). Thus, the normally efficient metabolism of fatty acids and pyruvate is seriously retarded by hypoxic conditions and under these conditions the anaerobic metabolism of glucose, the only alternative source of energy, is selectively increased. In fact, the extent of the survival of the hypoxic heart is directly dependent on its ability to increase its utilization of glucose (Cascarano, Chick, and Seidman, 1968; Weissler et al., 1968). The survival of the anoxic failing heart is therefore directly related to the availability of glucose to the myocardial cell, which in turn is directly dependent upon the transport facility offered by insulin. Thus, glucose and insulin together play a vital role in maintaining the emergency mechanisms of energy production in the failing hypoxic heart.

\section{Secretion of insulin in heart failure}

The onset of heart failure, particularly left ventricular failure, is immediately associated with reflex circulatory changes which maintain cerebral blood flow by sustaining the blood pressure. These primary circulatory adaptations are brought about by an increase in sympathetic nervous activity, which results in increased pumping activity of the heart accompanied by a reduction in flow to the majority of the regional vascular territories due to vasoconstriction. This intense sympathetic activity is accompanied by an increased liberation of catecholamines, both from the 
sympathetic nerve endings and from the adrenal medulla (Chidsey, Braunwald, and Morrow, 1965). Though these elegant adaptive mechanisms are vital to maintain the integrity of the cerebral blood flow, their secondary effects are often undesirable, particularly if the heart failure is unresponsive and the intense sympathetic drive maintained for more than a short time. One of the deleterious effects of the maintenance of such intense sympathetic activity is its little-known but possibly vital effect in depressing insulin release from the beta-cells of the islets of Langerhans in the pancreas.

Hyperglycaemia has frequently been noted as an accompaniment of the low cardiac output state associated with circulatory shock after myocardial infarction (Ellenberg, Osserman, and Pollack, 1952; MacKenzie et al., 1964; Taylor et al., 1969). The increase in blood sugar at the onset of shock is predominantly due to the increased breakdown of the glycogen stores resulting from the reflex increase in sympathetic nervous activity. However, the hepatic stores of glycogen are relatively small, and while some repletion of the glycogen stores may result from gluconeogenesis secondary to the increased secretion of adrenocortical steroids, the persistence of hyperglycaemia in these patients led to the suspicion that failure of insulin secretion might play a possible role in this respect. Studies of the insulin secretion response to intravenous tolbutamide or glucose demonstrated a nearly complete suppression of insulin release in these patients (Taylor et al., 1969; Allison et al., 1969). Serial studies of the insulin secretion response in the survivors and in patients with uncomplicated myocardial infarction confirmed the close relation between the facility with which insulin was released and the clinical state of the patient (Taylor et al., 1969). In view of this close relation between insulin liberation and the degree of power failure of the heart, the studies were extended to patients with the low cardiac output syndrome after open-heart operation (Majid et al., 197I) and to patients in severe chronic heart failure due to valvular disease (Sharma et al., 1970). In both groups of patients, severe heart failure was accompanied by a profound suppression of insulin secretion and serial studies again showed the close correlation between insulin release and the clinical state of the patient.

These observations suggest that pumping failure of the heart, whatever the cause, is associated with a reduction or even complete suppression of insulin secretion. Two mechanisms are probably involved.
I A reduction in pancreatic blood flow.

2 Increased sympathetic nervous activity.

The large reduction in splanchnic and pancreatic blood flow that accompanies the redistribution of regional blood flow in cardiac failure may reduce the insulin response by attenuation of the stimuli of insulin secretion; on this point there is no direct experimental evidence. There is, however, a considerable body of experimental and clinical evidence that the sympathetic nervous system plays a vital role in the control of insulin secretion (Taylor and Majid, 197I). Adrenaline and noradrenaline both inhibit the release of insulin from the pancreas in vitro (Coore and Randle, 1964), in animals (Kris et al., 1966; Altszuler et al., 1967), and in man (Porte et al., 1966). Excessive secretion of endogenous catecholamines in patients with phaeochromocytoma tumours is associated with hyperglycaemia and inhibition of insulin secretion (Wilber, Turtle, and Crane, 1966). Infusion of catecholamines into the pancreatic artery of the dog results in severe but reversible histological changes confined to the islet beta-cells (Loubatieres et al., 1965). Adrenergic alphastimulation and beta-blockade both suppress insulin release in normal man while alphablockade and beta-stimulation both potentiate insulin release (Majid et al., 1970). These observations show that the sympathetic nervous system has an important role in the control of insulin secretion. In heart failure, where sympathetic nervous activity may be intense, this powerful influence may result in suppression of insulin release even in the presence of hyperglycaemia, the normal stimulus to insulin secretion. The evidence suggests that this suppression of insulin release is due to the direct effects of sympathetically mediated vasoconstriction of the pancreas potentiated by the increased levels of circulating catecholamines.

The potential therapeutic importance of these arguments has recently been demonstrated by their application to the treatment of patients in severe heart failure (Majid et al., 1970). Insulin suppression in these patients was immediately relieved by alpha-blockade with phentolamine and by beta-stimulation with isoprenaline and the effect of the two drugs together was summative. In the past, the use of these two agents in patients with a low cardiac output state has been largely concerned with their direct haemodynamic effects, but these recent observations suggest that they may play an additional and vital role in the metabolic support of the failing heart by release of the associated insulin suppression. 


\section{Treatment of heart failure with insulin and glucose}

The interrelation between insulin activity, glucose consumption, and energy production by the heart came into prominence at the beginning of this century after the discovery by Knowlton and Starling (1912) that the addition of pancreatic extract increased the sugar consumption of the heart in diabetic dogs and cats to normal. Later, Clark (I9I6) showed that this increased use of sugar by the heart was directly related to the development of additional contractile energy; Hepburn and Latchford (1922) also showed that the addition of insulin to the perfusate through the isolated rabbit heart tripled its sugar consumption. In the light of recent metabolic studies, Burn and Dale (1924) made the important observation that the addition of insulin to the isolated heart accelerated the removal of glucose without change in its respiratory quotient of unity, and Visscher and Müller (1927) concluded that insulin resulted in an increase in myocardial contractility which was independent of processes involving oxidative metabolism. The potential therapeutic significance of these findings was directly confirmed by Bayliss, Müller, and Starling (1928) who observed that the addition of insulin and glucose to the isolated perfused heart postponed the onset of failure, and by Gremels (I940) who noticed that heart failure in the isolated heart-lung preparation was invariably preceded by a decrease in glucose utilization by the heart. In view of these and other more recent demonstrations that the failing heart is glucose dependent, and that the therapeutic efficiency of the digitalis glycosides are also dependent on glucose - transport (Berman, Masuoka, and Saunders, 1957), it is remarkable that so little clinical attention has been paid to these potentially important therapeutic observations.

A number of early reports claimed to have shown clinical benefit in patients in heart failure from the use of oral or intravenous - glucose, and some noted the disappearance of electrical alternation during such treatment. However, it is possible that the large amounts of glucose given in these early studies may have achieved some of their benefit by an induced sugar diuresis, particularly in view of the recent finding of insulin suppression in such patients. The introduction of insulin in 1922 aroused immediate clinical interest in its use in heart failure. A number of reports claimed significant clinical benefit from the use of insulin and glucose, and it is particularly noteworthy that some claimed significant improvement in patients resistant to other treatments, including digitalis. Though some more recent reports have claimed equally impressive clinical results with insulin and glucose in congestive heart failure (Laborit, I963), objective haemodynamic studies do not appear to have been undertaken and clinical interest has waned.

Insulin and glucose have frequently been advocated for the treatment of angina pectoris. In a review of the subject, Smith (1933) added a further six well-documented cases of angina resistant to other treatments, who experienced complete symptomatic relief with insulin and glucose treatment. These careful studies did not arouse the clinical and investigative interest they deserved, and the haemodynamic assessment of the effects of insulin and glucose in angina pectoris appears to have been entirely neglected.

Contemporary interest in the use of insulin and glucose in heart disease has been nearly entirely directed towards their effects in myocardial infarction. Early reports were concerned with the effects of insulin and glucose treatment on survival after resuscitation from cardiac arrest subsequent to acute myocardial infarction; significant benefits were claimed (Laborit, 1963). More recent attention has been devoted to the prevention and correction of cardiac dysrhythmias after myocardial infarction (Sodi-Pallares et al., 1962; Lundman and Orinius, 1965; Mittra, 1965). Though insulin has been shown to be essential for glucose utilization and the maintenance of a normal intracellular potassium concentration, the results of studies of the prophylactic benefit of insulin and glucose against dysrhythmias developing after myocardial infarction have been therapeutically disappointing. Though many reports have claimed that insulin, glucose, and potassium treatment afford significant protection against the development of dysrhythmias after myocardial infarction, a number of more carefully designed studies failed to confirm these findings (Sievers et al., 1966; Autio et al., 1966; Pilcher et al., 1967; Medical Research Council Report, 1968). However, the results of these trials are difficult to interpret due to the different criteria for the selection of patients, different regimens of treatment employed, and the different methods of evaluation of results. The potential value of such treatment must await proof that myocardial cells in an area of infarction are potassium depleted and that the administration of glucose and additional insulin is capable of restoration of the intracellular potassium of these anoxic fibres. Until such experimental evidence is forthcoming, the place of insulin, glucose, and potassium therapy in the 
prevention of cardiac dysrhythmias will remain conjectural.

\section{Resumé}

The failing anoxic heart is nearly completely dependent upon the metabolism of glucose to maintain its energy requirements. Though this emergency mechanism cannot supply more than a small proportion of the energy required by the normal heart, in heart failure even this small contribution to energy production may suffice to maintain essential contractile function for short periods. The availability of glucose to the myocardial cell is completely dependent upon an adequate supply of insulin. In severe heart failure insulin release is suppressed by the combined effects of low pancreatic blood flow and increased catecholamine secretion. In these circumstances the emergency mechanisms of myocardial metabolism which utilize glucose may break down through lack of insulin. Though it has long been known that insulin and glucose may resuscitate the failing isolated heart, the role of insulin and the control of its secretion in heart failure appears to have been largely neglected despite its potentially important therapeutic significance.

\section{References}

Allison, S. P., Chamberlain, M. J., and Hinton, P. (I969). Intravenous glucose tolerance, insulin, glucose, and free fatty acid levels after myocardial infarction. British Medical fournal, 4, 776.

Altszuler, N., Steele, R., Rathgeb, I., and De Bodo, R. C. (1967). Glucose metabolism and plasma insulin levels during epinephrine infusion in the dog. American fournal of Physiology, 212, 677.

Autio, L., Hakkila, J., Härtel, G., and Ikkala, E. (I966). Anticoagulants and Sodi-Pallares infusion in acute myocardial infarction. Acta Medica Scandinavica, 179, 355.

Bayliss, L. E., Müller, E. A., and Starling, E. H. (1928). The action of insulin and sugar on the respiratory quotient and metabolism of the heartlung preparation. Fournal of Physiology, 65, 33.

Berman, D. A., Masuoka, D. T., and Saunders, P. R. (1957). Potentiation by ouabain of contractile response of myocardium to glucose. Science, 126, 746.

Burn, J. H., and Dale, H. H. (1924). On the location and nature of the action of insulin. Fournal of Physiology, 59, 164.

Cascarano, J., Chick, W. L., and Seidman, L. (1968). Anaerobic rat heart: effect of glucose and Krebs cycle metabolite on rate of breathing. Proceedings of the Society for Experimental Biology and Medicine, 127, 25.

Chidsey, C. A., Braunwald, E., and Morrow, A. G. (1965). Catecholamine excretion and cardiac stores of norepinephrine in congestive heart failure. American fournal of Medicine, 39, 442.

Clark, A. H. (1916). The interrelation of the surviving heart and pancreas of the dog in sugar metabolism. Fournal of Experimental Medicine, 24, 621.

Coore, H. G., and Randle, P. J. (1964). Regulation of insulin secretion studied with pieces of rabbit pancreas incubated in vitro. Biochemical fournal, 93, 66.

Ellenberg, M., Osserman, K. E., and Pollack, H. (1952). Hyperglycemia in coronary thrombosis. Diabetes, I, 16.

Gremels, H. (1940). Úber die Beziehungen des Kohlehydratstoffwechsels zur Physiologie und Pharmakologie der Herzenergetik. Archiv für experimentelle Pathologie und Pharmacologie, 194, 629.

Hepburn, J., and Latchford, J. K. (1922). Effect of insulin (pancreatic extract) on the sugar consumption of the isolated surviving rabbit heart. American Fournal of Physiology, 62, 177.

Knowlton, F. P., and Starling, E. H. (1912). Experiments on the consumption of sugar in the normal and the diabetic heart. Fournal of Physiology, 45, 146.

Kris, A. O., Miller, R. E., Wherry, F. E., and Mason, J. W. (1966). Inhibition of insulin secretion by infused epinephrine in rhesus monkeys. Endocrinology, 78, 87 .

Laborit, H. (1963). Le traitement des insuffisances cardiovasculaires et de l'infarctus du myocarde par l'association insuline, glucose hypertonique, sels de potassium. Presse Médicale, 71, I.

Loubatieres, A., Mariani, M. M., Chapal, J., Taylor, J., Houarean, M. A., and Rondot, A. M. (I965). Action novice de l'adrenaline pour la structure histologique des iliots de Langerhans du pancreas; action protectrice de la dihydroergotamine. Diabetologia, 1, 13.

Lundman, T., and Orinius, E. (1965). Insulin-glucosepotassium infusion in acute myocardial infarction. Acta Medica Scandinavica, 178, 525.

MacKenzie, G. J., Taylor, S. H., Flenley, D. C., McDonald, A. H., Staunton, H. P., and Donald, K. W. (1964). Circulatory and respiratory studies in myocardial infarction and cardiogenic shock. Lancet, 2, 825 .

Majid, P. A., Ghosh, P., Pakrashi, B. C., Ionescu, M., Dykes, J. R. W., and Taylor, S. H. (I971). Insulin secretion after open-heart surgery with particular respect to pathogenesis of low cardiac output state. British Heart fournal, 33, 6.

Majid, P. A., Saxton, C., Dykes, J. R. W., Galvin, M. C., and Taylor, S. H. (1970). Autonomic control of insulin secretion and the treatment of heart failure. British Medical fournal, 4, 328.

Medical Research Council Working-Party on the Treatment of Myocardial Infarction (1968). Potassium, glucose, and insulin treatment for acute myocardial infarction. Lancet, 2, 1355.

Mittra, B. (1965). Potassium, glucose, and insulin in treatment of myocardial infarction. Lancet, 2, 607.

Owen, P., Thomas, M., and Opie, L. (1969). Relative changes in free-fatty-acid and glucose utilisation by ischaemic myocardium after coronary-artery occlusion. Lancet, $1,1187$.

Pilcher, J., Etishamudin, M., Exon, P., and Moore, J. (1967). Potassium, glucose, and insulin in myocardial infarction. Lancet, $\mathbf{r}$, 1 rog.

Porte, D., Graber, A. L., Kuzuya, T., and Williams, R. H. (1966). The effect of epinephrine on immunoreactive insulin levels in man. Fournal of Clinical Investigation, 45, 228.

Sayen, J. J., Sheldon, W. F., Peirce, G., and Kuo, P. T. (1954). Motion picture studies of ventricular muscle dynamics in experimental localized ischemia, correlated with myocardial oxygen tension and electrocardiograms. Fournal of Clinical Investigation, 33, 962.

Scheuer, J. (1967). Myocardial metabolism in cardiac hypoxia. American fournal of Cardiology, 19, 385. 
Sharma, B., Majid, P. A., Pakrashi, B. C., Dykes, J. R. W., and Taylor, S. H. (1970). Insulin secretion in heart failure. British Medical fournal, 2, 396.

Sievers, J., Lindh, J., Johansson, B. D., and Karnell, J. (1966). Acute myocardial infarction treated by glucose-insulin-potassium infusion. Cardiologia, 49, 239.

Smith, K. Shirley (1933). Insulin and glucose in the treatment of heart disease. British Medical fournal, I, 693.

Sodi-Pallares, D., Testilli, M. R., Fishleder, B. L., Bisteni, A., Medrano, G. A., Friedland, C., and De Micheli, A. (1962). Effects of an intravenous infusion of a potassium-glucose-insulin solution on the electrocardiographic signs of myocardial infarction. A preliminary clinical report. American fournal of Cardiology, 9, 166.

Taylor, S. H., and Majid, P. A. (1971). Insulin and the heart. Fournal of Molecular and Cellular Cardiology. In the press.
Taylor, S. H., Saxton, C., Majid, P. A., Dykes, J. R.W., Ghosh, P., and Stoker, J. B. (1969). Insulin secretion following myocardial infarction with particular respect to the pathogenesis of cardiogenic shock. Lancet, 2, 1373.

Tennant, R., and Wiggers, C. J. (1935). The effect of coronary occlusion on myocardial contraction. American fournal of Physiology, 112, 351.

Visscher, M. B., and Müller, E. A. (1927). The influence of insulin on the mammalian heart. Fournal of Physiology, 62, 341.

Weissler, A. M., Kruger, F. A., Baba, N., Scarpelli, D. C., Leighton, R. F., and Gallimore, J. K. (1968). Role of anaerobic metabolism in the preservation of functional capacity and structure of anoxic myocardium. Fournal of Clinical Investigation, 47, 403.

Wilber, J. F., Turtle, J. R., and Crane, N. A. (1966) Inhibition of insulin secretion by a pheochromocytoma. Lancet, 2, 733.

It will be obvious to subscribers that the small size of the present issue is attributable to the postal strike. 